\title{
THE
}

\section{Combustion Organic Aerosol as Cloud Condensation Nuclei in Ship Tracks}

\author{
Lynn M. Russell \\ Kevin J. Noone \\ Ronald J. Ferek \\ Robert Pockalny \\ University of Rhode Island, rpockalny@uri.edu \\ Richard C. Flagan
}

See next page for additional authors

Follow this and additional works at: https://digitalcommons.uri.edu/gsofacpubs

Terms of Use

All rights reserved under copyright.

\section{Citation/Publisher Attribution}

Russell, L.M., K.J. Noone, R.J. Ferek, R.A. Pockalny, R.C. Flagan, and J.H. Seinfeld, 2000: Combustion Organic Aerosol as Cloud Condensation Nuclei in Ship Tracks. J. Atmos. Sci., 57, 2591-2606. doi: 10.1175/1520-0469(2000)0572.0.CO;2.

Available at: https://doi.org/10.1175/1520-0469(2000)0572.0.c0;2

This Article is brought to you for free and open access by the Graduate School of Oceanography at DigitalCommons@URI. It has been accepted for inclusion in Graduate School of Oceanography Faculty Publications by an authorized administrator of DigitalCommons@URI. For more information, please contact digitalcommons-group@uri.edu. 


\section{Authors}

Lynn M. Russell, Kevin J. Noone, Ronald J. Ferek, Robert Pockalny, Richard C. Flagan, and John H. Seinfeld 


\title{
Combustion Organic Aerosol as Cloud Condensation Nuclei in Ship Tracks
}

\author{
LYNN M. RUSSELL \\ Department of Chemical Engineering, Princeton University, Princeton, New Jersey \\ KEVIN J. NOONE \\ Meteorological Institute, Stockholm University, Stockholm, Sweden \\ RONALD J. FEREK* \\ Department of Atmospheric Sciences, University of Washington, Seattle, Washington \\ RoBert A. POCKALNY \\ Graduate School of Oceanography, University of Rhode Island, Narragansett, Rhode Island \\ Richard C. Flagan and John H. Seinfeld \\ Department of Chemical Engineering, California Institute of Technology, Pasadena, California
}

(Manuscript received 15 May 1996, in final form 7 June 1997)

\begin{abstract}
Polycyclic aromatic hydrocarbons (PAHs) have been sampled in marine stratiform clouds to identify the contribution of anthropogenic combustion emissions in activation of aerosol to cloud droplets. The Monterey Area Ship Track experiment provided an opportunity to acquire data on the role of organic compounds in ambient clouds and in ship tracks identified in satellite images. Identification of PAHs in cloud droplet residual samples indicates that several PAHs are present in cloud condensation nuclei in anthropogenically influenced air and do result in activated droplets in cloud. These results establish the presence of combustion products, such as PAHs, in submicrometer aerosols in anthropogenically influenced marine air, with enhanced concentrations in air polluted by ship effluent. The presence of PAHs in droplet residuals in anthropogenically influenced air masses indicates that some fraction of those combustion products is present in the cloud condensation nuclei that activate in cloud. Although a sufficient mass of droplet residuals was not collected to establish a similar role for organics from measurements in satellite-identified ship tracks, the available evidence from the fraction of organics present in the interstitial aerosol is consistent with part of the organic fraction partitioning to the droplet population. In addition, the probability that a compound will be found in cloud droplets rather than in the unactivated aerosol and the compound's water solubility are compared. The PAHs studied are only weakly soluble in water, but most of the sparse data collected support more soluble compounds having a higher probability of activation.
\end{abstract}

\section{Introduction}

The indirect effect of aerosols on climate is based on the influence of anthropogenic aerosol emissions (or formation of aerosol by gas-to-particle conversion of anthropogenic emissions) on the number concentration of cloud condensation nuclei $(\mathrm{CCN})$, with a resulting im-

*Current affiliation: Office of Naval Research, Washington, D.C.

Corresponding author address: Dr. Lynn M. Russell, A317 Engineering Quadrangle, Princeton University, Princeton, NJ 08544. E-mail: lrussell@princeton.edu pact on cloud droplet number concentration (CDNC) and sizes (National Research Council 1996). To assess the importance of the indirect climatic effect of aerosols, it is necessary to relate mass emissions of aerosols and their precursors (such as $\mathrm{SO}_{2}$ ) to aerosol number concentrations, to $\mathrm{CCN}$ concentrations (not all particles act as $\mathrm{CCN}$ ), to $\mathrm{CDNCs}$, and finally to cloud optical properties. An important link in this chain is the CCN properties of anthropogenic aerosols. Whereas the CCN properties of inorganic sulfate aerosols are reasonably well characterized, those of organic particles emitted from combustion processes are not understood. There exist neither adequate laboratory studies nor field measurements of the $\mathrm{CCN}$ properties of combustion-derived 
TABLE 1. Previous measurements of polycyclic aromatic hydrocarbons, quinones, and ketones in ship and engine emissions, urban areas, and marine aerosol. ND, compound not detected. NR, compound not resolved.

\begin{tabular}{|c|c|c|c|c|c|}
\hline \multirow[b]{2}{*}{ Compound } & \multicolumn{2}{|c|}{ Reported concentrations ${ }^{\mathrm{a}}$} & \multicolumn{3}{|c|}{ Engine emissions } \\
\hline & $\begin{array}{c}\text { Urban } \\
\text { (Pasadena) } \\
\mu \mathrm{g} \mathrm{m}^{-3}\end{array}$ & $\begin{array}{c}\text { Marine (San } \\
\text { Nicolas) } \\
\mu \mathrm{g} \mathrm{m}^{-3}\end{array}$ & $\begin{array}{c}\text { Fuel oil } \\
\text { container ship } \\
\mu \mathrm{g} \mathrm{m}^{-3}\end{array}$ & $\begin{array}{c}\text { Gas oil barge } \\
\mu \mathrm{g} \mathrm{m}^{-3}\end{array}$ & $\begin{array}{c}\text { Diesel } \\
\text { emissions } \\
\mu \mathrm{g} \mathrm{km}^{-1}\end{array}$ \\
\hline \multicolumn{6}{|c|}{ Polycyclic aromatic hydrocarbons } \\
\hline Anthracene & NR & $<0.01$ & 0.197 & 0.7 & 1.60 \\
\hline Phenanthrene & NR & $<0.01$ & 8.77 & 20 & 12.20 \\
\hline Fluoranthene & 0.13 & $<0.01$ & 3.89 & 5.2 & 13.00 \\
\hline Pyrene & 0.17 & $<0.01$ & 4.67 & 5.4 & 22.60 \\
\hline Benzo[a]fluorene & NR & $<0.01$ & NR & NR & 1.90 \\
\hline Benzo[b]fluorene & NR & $<0.01$ & 1.64 & 8.5 & NR \\
\hline Benz[a]anthracene & 0.25 & $<0.01$ & 0.249 & $<0.009$ & 3.60 \\
\hline Chrysene & 0.43 & $<0.01$ & 2.572 & 1.6 & 9.90 \\
\hline Triphenylene & 0.43 & $<0.01$ & 5.856 & 6 & NR \\
\hline Benzo[a]pyrene & 0.44 & $<0.01$ & 0.058 & 0.03 & 1.30 \\
\hline Benzo[k]fluoranthene & 0.93 & $<0.01$ & $<0.026$ & 2.8 & 2.60 \\
\hline Benzo[e]pyrene & 1.20 & $<0.01$ & 0.057 & 0.03 & 2.70 \\
\hline Perylene & NR & $<0.01$ & 0.896 & 0.1 & 1.00 \\
\hline Indeno[1,2,3-cd]pyrene & 0.42 & $<0.01$ & 0.183 & $<0.01$ & ND \\
\hline Benzo[ghi]perylene & 4.43 & $<0.01$ & 0.678 & $<0.01$ & 1.60 \\
\hline Dibezn[a,h]anthracene & NR & $<0.01$ & 1.569 & $<0.03$ & ND \\
\hline \multicolumn{6}{|c|}{ Polycyclic aromatic ketones and quinones } \\
\hline 9H-Fluoren-9-one (fluorenone) & NR & $<0.01$ & NR & NR & 65.00 \\
\hline 9,10-Anthracenedione (anthraquinone) & NR & $<0.01$ & NR & NR & 23.50 \\
\hline 9H-Xanthen-9-one (xanthone) & NR & $<0.01$ & NR & NR & 2.70 \\
\hline 7H-Benz[de]anthracen-7-one & 0.84 & $<0.01$ & NR & NR & 5.60 \\
\hline
\end{tabular}

a Diesel emission concentrations are reported from Rogge et al. (1993a).

${ }^{b}$ Pasadena ambient and San Nicolas Island ambient concentrations are reported from Rogge et al. (1993c).

${ }^{c}$ Marine vessel emissions are reported from Banisoleiman et al. (1994). Values reflect maximum measured during emission trials.

carbonaceous aerosols to allow one to predict reliably the effect of such aerosols on cloud droplet activation.

Ship tracks provide an ideal mechanism for studying effects of anthropogenic emissions on marine stratocumulus clouds. The present work provides an initial investigation of the fate of organic aerosols emitted from ship exhaust in the marine stratocumulus layer. A major question is, to what extent can the microphysical features of ship tracks be attributed to organic aerosols emitted in the combustion exhaust of ships?

There is ample evidence for an organic signature of combustion products in the aerosol phase of combustion emissions (Hildemann et al. 1989, 1991; Menichini 1992; Rogge et al. 1993a; Henderson et al. 1984; Banisoleiman et al. 1993; J. Tilman 1995, personal communication). Menichini (1992) has reviewed the use of "spy polycyclic aromatic hydrocarbons (PAHs)" to identify emissions of vehicles and coal-burning and industrial plants. Banisoleiman et al. (1994) report high concentrations of PAHs in the emissions of two fuel oil-powered ships (a ferry and a container ship) and of a gas oil-powered barge as summarized in Table 1. Phenanthrene, fluoranthene, pyrene, triphenylene, chrysene, and benzo[b]fluorene appeared in all samples in concentrations exceeding $1 \mu \mathrm{g} \mathrm{m}^{-3}$. Trace amounts of benzo[g,h,i]perylene, dibenzo[a,h]anthracene, and indeno[1,2,3-c,d]pyrene were also reported. These authors estimate that the total worldwide emissions of aerosol- phase PAHs from marine vessels are between 66 and 466 metric tons (Banisoleiman et al. 1993). PAH signatures have been found in ambient urban and anthropogenically influenced samples (Rogge et al. 1993c). As noted, the key question for climatic effects is to what extent the anthropogenic organic aerosol mass creates additional CCN. Frisbie and Hudson (1993) and Hudson (1991) have, in one study, shown that anthropogenic aerosol increased the concentrations of efficient $\mathrm{CCN}$.

Early efforts to speciate the organic fraction of urban aerosol were undertaken by Cronn et al. (1977), who developed a method for using high-resolution mass spectrometry to identify individual organic compounds in the atmospheric aerosol. Duce et al. (1983) collected field samples of marine organic aerosol providing evidence that background oceanic sources contribute straight chain alkanes of 9 to 20 carbons, as well as organic acids. Few other species were found at levels exceeding $1 \mathrm{ng} \mathrm{m}^{-3}$ in the marine air samples (Duce and Gagosian 1982; Duce et al. 1983; Schneider et al. 1983; Kawamura and Gagosian 1987; Peltzer and Gagosian 1987). Sicre et al. (1990) have used long-chain unsaturated ketones in aerosol particles as tracers for long-range transport.

The data of Rogge et al. (1993c) provide an indication of the contrast in organic aerosols between background marine sources at San Nicolas Island 100 miles west of Los Angeles, California, and urban sources at seven 
inland sites. The off-coast site showed straight chain alkanes in concentrations of up to $300 \mathrm{ng} \mathrm{m}^{-3}$, consistent with earlier work (Duce et al. 1983), but most other species were below the detection limit for their method. The high PAH concentration and the large quantities of branched alkanes resulting in unresolved spectral peaks at Rubidoux and Pasadena, California, contrast markedly with the low background concentration at the upwind island site, suggesting a characteristic signature for marine sources of low concentrations and straightchain alkanes, compared to the urban PAH and branched alkane species. Anthropogenic PAH tracers such as fluoranthene, pyrene, benz[a]anthracene, and benzo[e]pyrene were found at levels between 100 and 4000 $\mathrm{ng} \mathrm{\textrm {m } ^ { - 3 }}$ at downtown Los Angeles but were below the PAH detection limit of $30 \mathrm{ng} \mathrm{m}^{-3}$ at San Nicolas Island (Rogge et al. 1993c). Grosjean's (1983) measurements of PAHs are consistent with these concentrations.

Recent studies of the total organic content of aerosol allow estimation of the lifetime of organic aerosols in the atmosphere and, consequently, the range over which such compounds may be transported (Novakov and Penner 1993). The observations of Novakov and Penner (1993) suggest that in regions downwind of major continental sources, organics can be a significant fraction of the marine aerosol that serves as CCN. These observations provided evidence that organics constitute part of CCN active particles, either in an internal or external mixture, with inorganic salts. Distinguishing the type of mixture of organics, as well as the potential importance of the aging that occurred in the aerosol during the transport from the continental sources, have important consequences for marine cloud formation. Calculations of Novakov and Penner (1993) suggest that, on average, particles larger than $0.05 \mu \mathrm{m}$ contain organic mass, and that at $0.5 \%$ supersaturation, those particles are active as $\mathrm{CCN}$. Although their dataset is limited and does not relate directly to marine stratus clouds (where supersaturations typically do not exceed $0.1 \%$ ), their data indicate that, if the size of particles activated at $0.5 \%$ supersaturation is assumed to be 0.05 $\mu \mathrm{m}$, then the mass of organics present at, and above, this size is required to account for the number of $\mathrm{CCN}$ measured. Simultaneous quantification of organic and sulfate mass on shorter timescales as well as more detailed size and time-resolved data would, however, be needed to identify whether the organics are present in an internal or an external aerosol mixture. In addition, to establish the role of organics in marine $\mathrm{CCN}$, one needs the CCN activation spectrum for the organic aerosol and the composition of cloud droplet residuals (the particles remaining after cloud drops have been evaporated).

Analysis of continental fog droplet residual composition was undertaken in the Po Valley study by employing a counterflow virtual impactor (CVI) (Ogren et al. 1985; Noone et al. 1988, 1992). Data suggested a chemical difference in the residual composition of drop- lets, which would be consistent with an external mixture of hydrophobic and hygroscopic particle populations. Moreover, the composition of the droplet residuals was consistent with the hygroscopic, or soluble, population. In addition to the highly polluted anthropogenic nature of the Po Valley aerosol, the authors note that the thermodynamic conditions of the continental fogs they studied may not be representative of the conditions found in convective clouds and may lead to activation of far fewer particles (i.e., as few as $50 \%$ at circa $0.5-\mu \mathrm{m}$ diameter) than has been found in convective clouds. In experiments at Kleiner Feldberg, Germany, Hallberg et al. (1992) obtained results similar to those at Po Valley with chemical analysis of impactor samples by demonstrating that the insoluble fraction (elemental carbon) will preferentially remain in the interstitial aerosol rather than activating to cloud droplets.

The role of chemical composition in determining the hygroscopic properties of an aerosol has been well characterized for soluble inorganic species (Pruppacher and Klett 1978; Tang and Munkelwitz 1994). However, for many organic species little is known about their impact on nuclei activation to droplets in actual supersaturated environments. Hansson et al. (1990) have investigated the effect of hydrophobic organic coatings on particles consisting of aqueous salt solutions on the growth of particles. They measured these effects for tetracosane, octadecane, and dioctyl phthalate by measuring the change in the particle's growth by water uptake for a specified change in relative humidity as a function of the thickness of the coating applied to the particles. For all of the hydrocarbons studied, they found a decrease of $0.2 \%$ in this hygroscopic growth per nanometer of hydrophobic coating applied to $\mathrm{NaCl}_{(\mathrm{aq})}$ particles and $0.6 \%$ for $\left(\mathrm{NH}_{4}\right)_{2} \mathrm{SO}_{4(\mathrm{aq})}$ particles. Conversely, Andrews and Larson (1993) have shown that an organic coating of a water-soluble surfactant can increase the relative mass uptake of water at $90 \%$ relative humidity by $20 \%$ over that of uncoated black carbon particles. Wyslouzil et al. (1994) have demonstrated that a sulfate layer effectively increases the hygroscopic properties of hydrophobic black carbon particles (which do not take up water at $80 \%$ relative humidity), allowing a mass increase of $30 \%$ of the particle mass at $80 \%$ relative humidity. Weingartner et al. (1995) showed that the growth of combustion particles at high humidities is enhanced after aging $6 \mathrm{~h}$ in the collection chamber.

Saxena and Hildemann (1996) have estimated the solubilities of a number of organic aerosol species. Shulman et al. (1996) have suggested that particles containing partially soluble compounds such as carboxylic acids mixed with soluble components such as ammonium sulfate can serve as $\mathrm{CCN}$, although the diameter at which the particle activates is predicted to be higher than that of pure ammonium sulfate. Their work suggests a need for further characterization of the solubilities of organics in other classes. 


\section{Airborne sampling of interstitial and cloud droplet residual aerosol}

The Monterey Area Ship Track (MAST) experiment, conducted in June 1994, provided an opportunity to characterize and compare organic aerosol species, both in interstitial aerosol and droplet residual particles, present in ambient air masses as well as in ship track cloud lines. Samples of interstitial aerosol and cloud droplet residual particles were collected aboard the University of Washington C-131A aircraft. The 12 flights yielded 35 interstitial and below-cloud aerosol samples, 17 cloud droplet residual samples, and 24 blanks. Samples were subsequently analyzed to identify the organic species present. The collection and analysis method was designed to allow the identification of the maximum number of organic species from the limited particle samples possible from aircraft sampling of track features.

\section{a. Sample collection protocol}

Samples were collected on quartz fiber filters (Tissuquartz 2500-QAOT, Pallflex Corporation, Putnam, Connecticut) on two types of filter holders. Filter holders for collecting submicron aerosol on quartz substrates of $135-\mathrm{mm}$ diameter were constructed of anodized aluminum. The filter holders are sealed by an O-ring compressed by tightening a screw opposing a hinged support. The filter substrate rests on a support consisting of stainless steel wire mesh overlaying perforated aluminum supports. A Teflon ring is used to hold the quartz-filter substrate in place. Air is drawn into the aircraft through a shrouded whole aerosol inlet into a $2.5 \mathrm{~m}^{3}$ evacuable collection bag (Hegg et al. 1993). The flow rate of air over these filters is $100 \mathrm{~L} \mathrm{~min}^{-1}$.

A CVI was used to sample cloud droplets (Ogren et al. 1985; Noone et al. 1988). This device uses an opposing air stream to separate cloud droplets from the interstitial aerosol. The cloud droplets were then evaporated and sized with an optical particle counter. The cloud droplet residual samples from the CVI inlet were collected in stainless steel filter holders supporting 25mm-diameter quartz substrates (Gelman Sciences) (Ogren et al. 1985; Noone et al. 1988).

Prior to sampling, all quartz filters were baked overnight above $550^{\circ} \mathrm{C}$ (Rogge et al. 1993c) to remove background blank contamination. The filters were wrapped in foil and placed in petri dishes for baking. After cooling, the petri dishes were sealed with Teflon tape until use (up to 60 days).

Substrates for both submicrometer aerosol and droplet residuals were installed in, and removed from, the filter holders in a glove box at the field site. The glove box was lined with Teflon and supplied with a continuous stream of air stripped of water and organic vapor-phase constituents. Aerosol was removed from the clean airstream by a total particle filter. Sample holders were cleaned between consecutive samples with methanol and allowed to dry in the glove box. Exposed samples were stored in cleaned glass vials (Protocol B for VOC Sampling, U.S. Environmental Protection Agency) with Teflon lids (sealed externally with Teflon tape) that were then frozen for storage (at or below $0^{\circ} \mathrm{C}$ ). Samples were transported from the field site (Monterey, California) to the analysis center (Pasadena) in insulated containers packed with dry ice. Samples were then stored frozen (below $0^{\circ} \mathrm{C}$ ) for up to 6 months before analysis.

Each sample was collected with an in-field blank sample so that field and storage contamination could be quantified. For each flight, one of the six parallel filter holders was reserved as a blank. Samples were also stored in the glove box each day to provide an additional measurement of the sampling blank by checking the cleanliness of the glove box. Blanks and samples were analyzed by the identical procedure, and the masses of the compounds present in the daily blank were subtracted from the masses in the samples. The resulting mass was divided by the volume of air filtered to give the ambient concentration for all values reported here.

\section{b. Extraction and identification procedure}

Particulate matter was extracted from the filters using supercritical fluid extraction (SFE). The extraction uses high-purity $\mathrm{CO}_{2}$ (SFE grade $\mathrm{CO}_{2}$ with 2000 psi Helium, Air Products, Allentown, Pennsylvania) compressed in an extraction module equipped with a pump for adding solvent modifiers (model Prepmaster and MPA1, Suprex Corporation, Pittsburgh, Pennsylvania). The $135-\mathrm{mm}$ filters were folded and rolled into a $10-\mathrm{ml}$ cylindrical extraction vessel, $10 \mathrm{~cm}$ long and $1 \mathrm{~cm}$ diameter. The 25-mm filters were extracted using a $0.5-\mathrm{ml}$ extraction chamber.

The SFE unit was connected to the gas chromatograph (GC) via a heated transfer line (model 050-020, Suprex Corporation). At the GC inlet a cryotrap (Hewlett-Packard) was installed to concentrate the sample transferred from the SFE unit. The heated transfer line consists of 1/16-in. flexible stainless steel tubing in a heating jacket regulated by a proportional temperature controller set to $290^{\circ} \mathrm{C}$. Separation of chemical species was performed in a gas chromatograph (GC, model 5890, HewlettPackard, Wilmington, Delaware) using one of two columns. The first, designated HP-5MS (model HP-5MS, Hewlett-Packard), optimizes resolution with low carrier gas bleed at temperatures up to $320^{\circ} \mathrm{C}$. Its packing of $5 \%$ phenyl methyl siloxane is efficient for separating nonpolar and some polar compounds. The second DB1701 (model DB-1701, J and W Scientific, Folsom, California) column has a wider bore that is packed with $14 \%$ cyanopropylphenyl methylpolysiloxane. The HP$5 \mathrm{MS}$ column was conditioned for $12 \mathrm{~h}$ at $325^{\circ} \mathrm{C}$ before use, and the DB- 1701 at $280^{\circ} \mathrm{C}$. Both columns were characterized for the following procedures with a suite of over 50 standards, as summarized in Table 2. Detection limits for all species calculated for the flow rates 
TABLE 2. Characterization of detection limits by SFE/GC-MS for polycyclic aromatic hydrocarbon, quinone, and ketone standards used. NR, compound not resolved. NQ, compound not quantified.

\begin{tabular}{|c|c|c|c|c|c|c|}
\hline \multirow[b]{2}{*}{ Compound } & \multicolumn{2}{|c|}{ Carbon major mass } & \multicolumn{2}{|c|}{ Retention time } & \multicolumn{2}{|c|}{ Detection limit } \\
\hline & Index & $\begin{array}{c}\text { Spectral peaks } \\
\mathrm{M} / \mathrm{Z}\end{array}$ & $\begin{array}{l}\text { DB-1701 } \\
\min \end{array}$ & $\begin{array}{l}\mathrm{HP}-5 \mathrm{MS} \\
\min \end{array}$ & $\begin{array}{c}\text { DB-1701 } \\
\mu \mathrm{g}\end{array}$ & $\begin{array}{c}\mathrm{HP}-5 \mathrm{MS} \\
\mu \mathrm{g}\end{array}$ \\
\hline \multicolumn{7}{|c|}{ Polycyclic aromatic hydrocarbons } \\
\hline Anthracene & C-14 & $178, \quad 89, \quad 76$ & 39.53 & 69.74 & 0.173 & 0.023 \\
\hline Phenanthrene & C-14 & $178,89,76$ & 39.53 & 69.30 & NQ & 0.028 \\
\hline Fluoranthene & C-16 & $202,101,87$ & 53.00 & 82.42 & 0.031 & 0.023 \\
\hline Pyrene & C-16 & $202,101,88$ & 54.97 & 84.54 & 0.033 & 0.028 \\
\hline Benzo[a]fluorene & C-17 & $216,108,187$ & 59.24 & 88.99 & 0.068 & 0.152 \\
\hline Benzo[b]fluorene & $\mathrm{C}-17$ & $216,108,189$ & 60.01 & 89.73 & 0.078 & 0.180 \\
\hline Benz[a]anthracene & C-18 & $228,114,164$ & 69.39 & 98.33 & 0.036 & 0.039 \\
\hline Chrysene $^{\mathrm{a}}$ & $\mathrm{C}-18$ & $228,114,202$ & 69.69 & 98.75 & 0.029 & 0.073 \\
\hline Triphenylene ${ }^{\mathrm{a}}$ & C-18 & $228,114,202$ & 69.69 & 98.75 & NQ & NQ \\
\hline Benzo[a]pyrene ${ }^{b}$ & $\mathrm{C}-20$ & $252,126,113$ & 81.38 & 109.61 & 0.058 & 0.063 \\
\hline Benzo[k]fluoranthene $\mathrm{b}^{\mathrm{b}}$ & $\mathrm{C}-20$ & $252,126,112$ & 81.05 & 109.61 & NQ & NQ \\
\hline Benzo[e]pyrene & $\mathrm{C}-20$ & $252,126,113$ & 84.79 & NR & 0.070 & 0.363 \\
\hline Perylene & $\mathrm{C}-20$ & $252,126,113$ & 83.42 & 111.99 & 0.029 & 0.328 \\
\hline Indeno[1,2,3-cd]pyrene & $\mathrm{C}-22$ & $276,138,125$ & 94.21 & 122.32 & 0.034 & 0.368 \\
\hline Benzo[ghi]perylene & $\mathrm{C}-22$ & $276,138,125$ & 95.93 & 124.14 & 0.032 & 0.305 \\
\hline Dibezn[a,h]anthracene & $\mathrm{C}-22$ & $278,139,125$ & 95.03 & 122.98 & 0.034 & 1.124 \\
\hline \multicolumn{7}{|c|}{ Polycyclic aromatic ketones and quinones } \\
\hline 9H-Fluoren-9-one (fluorenone) & C-13 & $180,152,126$ & 39.06 & 67.23 & 0.124 & 0.046 \\
\hline 9,10-Anthracenedione (anthraquinone) & $\mathrm{C}-14$ & $180,208,152$ & 50.34 & 78.26 & 0.031 & 0.103 \\
\hline 9H-Xanthen-9-one (xanthone) & $\mathrm{C}-13$ & $196,168,139$ & 44.84 & 73.37 & 0.072 & 0.145 \\
\hline 7H-Benz[de]anthracen-7-one & $\mathrm{C}-17$ & $230,202,101$ & 72.89 & 99.94 & 0.063 & 0.412 \\
\hline
\end{tabular}

a Since the chromatographic elution peaks of chrysene and triphenylene were not resolved, their concentration are reported together.

b Since the chromatographic elution peaks of benzo[a]pyrene and benzo[k]fluoranthene were not resolved, their concentrations are reported together.

and collection times of each individual sample are tabulated in Russell (1995).

The extraction procedure begins with raising the sample pressure to $300 \mathrm{~atm}$ and the temperature to $150^{\circ} \mathrm{C}$. After a 50-min equilibration time, the pressure is ramped to $450 \mathrm{~atm}$ over $10 \mathrm{~min}$ while maintaining constant temperature. A valve is then opened for $10 \mathrm{~min}$ to allow the carrier $\mathrm{CO}_{2}$ and the volatilized aerosol species to flow through the heated transfer line into the GC inlet, where species solidifying at $-40^{\circ} \mathrm{C}$ are held as the $\mathrm{CO}_{2}$ carrier gas continues through to the GC vent. The SFE vessel is then equilibrated for an additional 10 min before another transfer step of $20 \mathrm{~min}$. During the transfer phases a modifier solution of $10 \%$ acetic acid in methanol is added to the $\mathrm{CO}_{2}$ carrier gas at a fixed volumetric rate of $5 \%$ in order to enhance extraction of polar compounds.

At the end of the extraction, the HP-5MS GC column is then heated in four stages: 1) from $-45^{\circ}$ to $35^{\circ} \mathrm{C}$ at $\left.20^{\circ} \mathrm{C} \mathrm{min}{ }^{-1}, 2\right)$ remaining at $35^{\circ} \mathrm{C}$ for an additional 5 $\min , 3)$ from $35^{\circ}$ to $320^{\circ} \mathrm{C}$ at a uniform heating rate of $2^{\circ} \mathrm{C} \mathrm{min}{ }^{-1}$, and 4) constant at $320^{\circ} \mathrm{C}$ for $5 \mathrm{~min}$. The procedure followed for the DB-1701 column is similar: 1) from $-45^{\circ}$ to $35^{\circ} \mathrm{C}$ at $\left.20^{\circ} \mathrm{C} \mathrm{min}{ }^{-1}, 2\right)$ remaining at $105^{\circ} \mathrm{C}$ for an additional $5 \mathrm{~min}, 3$ ) from $35^{\circ}$ to $280^{\circ} \mathrm{C}$ at a uniform heating rate of $2^{\circ} \mathrm{C} \mathrm{min}^{-1}$, and 4) constant at $280^{\circ} \mathrm{C}$ for $5 \mathrm{~min}$.

Compounds separated in the GC are detected in a quadrupole mass spectrometer using electron impact ionization (model 5989A, Hewlett-Packard). Concentrations are calculated both as a fraction relative to the total ions detected in each sample and by reference to external standards for the compounds noted in Table 1. The external standards were purchased from Accustandard (New Haven, Connecticut). The detection limit for the standards studied varied from $10 \mathrm{ng}$ to $1 \mu \mathrm{g}$. The effective detection limit in terms of atmospheric concentration varies with the amount of air volume sampled for each measurement. The blanks collected have been taken into account by subtracting the concentration of the corresponding blank for each sample.

\section{Organic species in marine stratus}

Chemical analysis of species from aircraft sampling of ship tracks is constrained by the limited flow volumes, the short sampling times, and the low flow rates available in flight. These limitations arise from the fast speed of aircraft and the difficulty of finding and following a ship track in real time. Identifying localized spatial characteristics associated with ship tracks requires a protocol optimized for obtaining the best chemical identification possible with as little as $1 \mathrm{~m}^{3}$ air. As a result of the constraints associated with the samples collected during MAST, the primary focus in the chemical analysis is the relative differences between the compositions of interstitial and residual aerosol. This information provides a characteristic signature for the air 
TABLE 3. Summary of samples analyzed presented as a matrix of sample type vs case day (total numbers of samples in and below cloud, and in and out of tracks and plumes).

\begin{tabular}{|c|c|c|c|c|c|c|c|}
\hline \multirow[b]{2}{*}{ Sample date } & \multirow[b]{2}{*}{ JDT } & \multicolumn{2}{|c|}{ Droplet residuals } & \multicolumn{2}{|c|}{ In-cloud interstitial } & \multicolumn{2}{|c|}{ Boundary layer aerosol } \\
\hline & & a) In track & b) Ambient & c) In track & d) Ambient & e) In plume & f) Background \\
\hline 1 Jun 1994 & 152 & 1 & 1 & 0 & 0 & 1 & 1 \\
\hline 8 Jun 1994 & 159 & 1 & 1 & 0 & 0 & 1 & 2 \\
\hline 9 Jun 1994 & 160 & 0 & 0 & 0 & 0 & 1 & 0 \\
\hline 11 Jun 1994 & 162 & 0 & 0 & 1 & 1 & 0 & 0 \\
\hline 12 Jun 1994 & 163 & 1 & 1 & 1 & 0 & 1 & 1 \\
\hline 15 Jun 1994 & 166 & 0 & 0 & 0 & 0 & 1 & 1 \\
\hline 17 Jun 1994 & 168 & 0 & 1 & 0 & 0 & 0 & 0 \\
\hline 21 Jun 1994 & 172 & 1 & 1 & 1 & 1 & 1 & 1 \\
\hline 27 Jun 1994 & 178 & 1 & 1 & 1 & 1 & 2 & 1 \\
\hline 28 Jun 1994 & 179 & 1 & 1 & 0 & 1 & 1 & 1 \\
\hline 29 Jun 1994 & 180 & 1 & 1 & 1 & 2 & 1 & 1 \\
\hline 30 Jun 1994 & 181 & 1 & 1 & 1 & 1 & 2 & 1 \\
\hline Totals & & 8 & 9 & 6 & 7 & 12 & 10 \\
\hline
\end{tabular}

masses and track features sampled. Compiling the results of the MAST samples, the organic species illustrate the variability in the background air masses sampled during the experiment. The eight ships sampled serve to characterize organic aerosol species from typical emissions of ships with diesel, gas, and steam turbine engines.

The MAST experiment involved the University of Washington C-131A, the U.K. Met. Office Research Flight C-130, the Research Vessel Glorita, the Naval Research Laboratory research airship, several naval and commercial vessels, and intensive satellite observations, measuring cloud and boundary layer charateristics in the stratus off the coast of Monterey in June 1994 (Durkee et al. 2000a,b). Aerosol physics and chemistry measurements aboard the $\mathrm{C}-131 \mathrm{~A}$ are reported elsewhere (Noone et al. 2000a,b). The methodology used for interstitial aerosol samples for organic speciation required collecting three bag samples of air for each composite measurement of the aerosol in and below cloud. A continuous total condensation nuclei counter measurement was used to manually trigger bag collection in flight. Below-cloud measurements include background samples [with condensation nuclei $(\mathrm{CN})$ concentrations near the average observed in the air mass] and plume samples (in sight of the ship's stack with $\mathrm{CN}$ concentrations roughly 100 times higher than the ambient). In-cloud measurements included interstitial aerosol in track (high droplet and $\mathrm{CN}$ ) and ambient (background levels of droplets and $\mathrm{CN}$ ), as well as cloud droplet residuals in track and ambient. The CVI samples were collected continuously during all track intersections and during ambient cloud transits, also using $\mathrm{CN}$ concentrations to distinguish track effluents.

To identify anthropogenic effects, we use PAHs as tracers for combustion emissions. The presence of PAHs, as well as polycyclic aromatic ketones and quinones (PAKs and PAQs, respectively), in the particulate phase of combustion emissions of petroleum products has been well documented (Rogge et al. 1993a; Banisoleiman et al. 1994). There is evidence that the concentrations of these compounds in the background marine atmosphere are significantly lower than those expected in regions impacted by anthropogenic emissions (Hildemann et al. 1991; Rogge et al. 1993c).

Ship emissions result in increased frequencies of detection of particulate PAHs and PAKs in the marine aerosol. The samples collected are summarized in Table 3. More PAHs, PAKs, and PAQs were identified in plume and track samples than in the background below- or incloud samples with the exception of background belowcloud detection of benzo[e]pyrene and ben$\mathrm{zo}[\mathrm{k}]$ fluoranthene. These results are summarized by the frequency distribution of the number of samples in which each of the compounds were detected in Fig. 1. This figure illustrates the number of samples in which each compound noted was detected. Figures $1 \mathrm{a}$ and $1 \mathrm{~b}$ show the cloud droplet residuals samples in and out of track; Figs. 1c and 1d, the interstitial samples; and Figs. 1e and 1f, the out-of-cloud aerosol samples. The out-of-cloud samples (Figs. 1e,f) illustrate clearly the difference between plume and background aerosol, with higher frequencies of detection of fluorenone, pyrene, fluoranthene, phenanthrene, benzo[a]fluorene, and benzo[b]fluorene in plume exhaust samples than in the background samples. The results illustrated in Fig. 1a are inconclusive since all of the in-track cloud droplet residual samples were below detection. However, the background aerosol also shows clear indications of anthropogenic influence from combustion emissions in the background boundary layer sampled air, particularly in the presence of benzo[e]pyrene and benzo[k]fluoranthene (or benzo[a]pyrene). This influence may be a result of continental sources advected over the ocean, or of exhaust from ships previously encountered by the air mass. Both of these explanations are consistent with supporting physical measurements (satellite retrievals, aerosol size dis- 


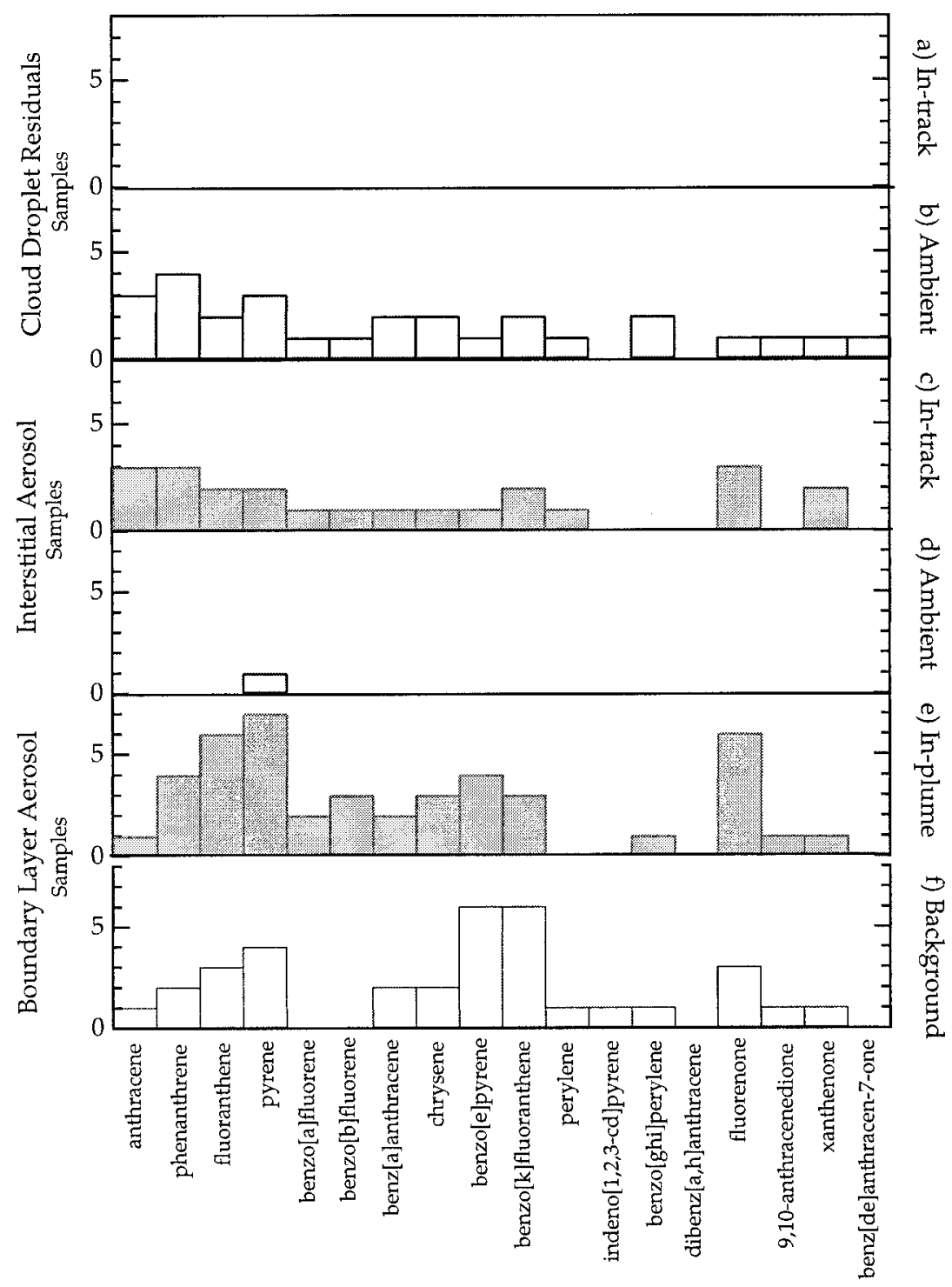

FIG. 1. Distribution of compounds detected for all samples (PAHs, PAQs, and PAKs) by class: (a) track residual droplets (in cloud), (b) ambient residual droplets (in cloud, out of track), (c) track interstitial (in cloud), (d) ambient interstitial (in cloud, not in track), (e) plume aerosol (below cloud), and (f) background boundary layer aerosol (below cloud, not in exhaust plume). All aerosol samples were collected with a $2-\mu \mathrm{m}$ effective upper cutoff using a $10 \mathrm{~m}^{3}$ bag sampler. All droplet residual samples were collected from a CVI inlet.

tributions, droplet concentrations) during the MAST experiment (Durkee et al. 2000a,b; Noone et al. 2000a,b).

The interstitial aerosol (Figs. 1c,d) also shows more PAHs and PAKs in track areas as compared to the ambient (out of track) interstitial aerosols. In fact, in the ambient background cloud, only one PAH was detected in one interstitial aerosol sample (pyrene). In track, the interstitial aerosol showed detectable amounts of most PAHs. As noted, the cloud droplet residual in-track samples (Fig. 1a) were inconclusive for determining the concentrations of PAHs in the in-cloud droplets. Since the CVI samples were collected at a constant flow rate (in- stead of the bag sampling method used for the interstitial aerosols), the sample volumes collected were, in general, too small to yield detectable levels of compounds in ship tracks. In addition, the decrease in mean droplet size in several of the tracks sampled may have sufficiently degraded the collection efficiency of the CVI inlet to also limit collection of droplets (Radke et al. 1989a,b; Durkee et al. 2000a,b). However, the presence of PAHs in the ambient cloud droplets is consistent with PAHs contributing to particles that activate to droplets or are scavenged by droplets at the supersaturations of convective marine clouds. 


\section{a. Variability of background conditions}

To assess the influence of ship emissions, it is helpful to first understand the variability in the background boundary layer particulate composition and the cloud droplet and aerosol compositions. Figure 2 describes the ambient conditions encountered during the MAST experiment for which samples were collected. The ambient values of anthracene, benzo[e]pyrene, and ben$\mathrm{zo}[\mathrm{k}]$ fluoranthene over $10 \mathrm{ng} \mathrm{m}^{-3}$ suggest that at least some of the ambient samples included anthropogenic aerosol sources, since the data of Rogge et al. (1993b) suggest that "clean" marine air as measured at San Nicolas Island are under this level, whereas urban areas are likely to have much higher concentrations (typically between 100 and $1000 \mathrm{ng} \mathrm{m}^{-3}$ ). The average suggests background levels that are consistent with anthropogenically influenced air masses, as indicated by the values reported in Table 1. However, the variability in samples, illustrated by the range of values for individual compounds in Fig. 2, accounts for the fact that several samples included concentrations below the detection limit.

Although the variability from day to day during the experiment complicates the interpretation of these average concentrations, accounting for the variability is important to illustrate the trends consistent throughout the dataset. With the exception of one sample showing a very low concentration of pyrene $\left(2 \mathrm{ng} \mathrm{m}^{-3}\right)$ on Julian decimal time (JDT) 180, all of the interstitial aerosol concentrations were below detection for PAHs, PAKs, and PAQs. By contrast, both the out-of-cloud aerosol and the in-cloud droplet residuals showed PAHs and PAKs. This observation is consistent with the majority of the PAHs and PAKs in the submicrometer aerosol being present in the fraction of aerosol that activated in the clouds observed here, and hence served as CCN.

All PAHs and PAKs detected in the boundary layer aerosol were also detected in the cloud droplet residuals at equal, or greater concentrations, both calculated on a basis of a cubic meter of air. The greater-than-ambient concentrations in the cloud droplet residuals may result, in part, from contamination of these out-of-track samples with in-track air during the sampling process since the CVI samples were manually switched based on the total aerosol concentration.

\section{b. Ship track and plume characteristics}

Concentrations of PAHs and PAKs in ship emissions vary with the type of ship and are thought to be influenced by the engine size, condition, and speed; ship tonnage; and fuel type and composition (Banisoleiman et al. 1994). Consequently, the emissions sampled during the MAST experiment are expected to include a variety of source compositions resulting in different PAH/PAK signatures. In addition, since bag samples of submicrometer aerosol were taken at different distances from the ship and in boundary layers of varying heights, the concentrations in the samples will have been influenced by different amounts of dilution. Source emission studies were not conducted for the specific ships sampled in this study, precluding ship-specific tracer identification. However, the quantities and species of PAHs were consistent with diluted ship engine emissions.

Figure 3 illustrates the variation found in the aerosol compositions in plumes and tracks sampled during MAST. For almost all PAHs, the range encompasses a span from over $100 \mathrm{ng} \mathrm{m}^{-3}$ to below the detection limit. In the out-of-cloud aerosol samples, four compounds are sufficiently concentrated in the plumes to exceed the ambient variability among all of the samples to result in measurable differences in Fig. 3. Those four PAH/ PAK tracers are pyrene, benzo[a]fluorene, ben$\mathrm{zo}$ [b]fluorene, and 9,10-anthracenedione.

In the cloud interstitial aerosol, there is a much clearer distinction than in the out-of-cloud aerosol between the in-track particles and the out-of-track particles, where there were no significant concentrations of PAHs, PAKs, or PAQs detected. The strongest signals in the in-track interstitial aerosol shown in Fig. 3 include five compounds (anthracene, phenanthrene, pyrene, benzo[e]pyrene, and fluorenone) with concentrations over $10 \mathrm{ng} \mathrm{m}^{-3}$. These concentrations are comparable to values reported for urban and industrial areas in Europe and the United States (Menichini 1992). In general, one would expect the concentrations of plume compounds to exceed those observed in the in-track interstitial aerosol, since the plume is closer to the ship and hence would be more concentrated. However, since the spatial extent of the plumes, sampled at a distance of 100-300 m behind the ship, was smaller and less predictable in flight, the in-plume bag samples were more likely to consist of several seconds (out of the $10 \mathrm{~s}$ required to fill the bag) of air from the edges of the plume, where the emissions were dilute. By contrast, the high in-track concentrations (at 1-3 $\mathrm{h}$ after emission) result from the uniform and predictable boundaries of well-mixed high aerosol number concentrations, which characterize the length of ship tracks (Durkee et al. 2000a,b).

A notable feature of Fig. 3 is the absence of PAHs in the in-cloud interstitial out-of-track aerosol, despite their presence in the below-cloud aerosol. There are, however, several PAHs in the in-cloud, out-of-track droplet residuals. As discussed above, the absence of PAHs in the ambient interstitial aerosol indicates that organics in aerosol below cloud serve as CCN and hence partition to the droplet phase, rather than the interstitial aerosol. This is supported by the presence of PAHs in the ambient droplet residual samples collected by the CVI (Fig. 2).

In track, as shown in Fig. 3, there remain significant PAHs in the interstitial aerosol (and the residual samples are inconclusive due to small sample volumes), suggesting two possibilities. The first would be to conclude that in ship tracks the particles containing PAHs do not 


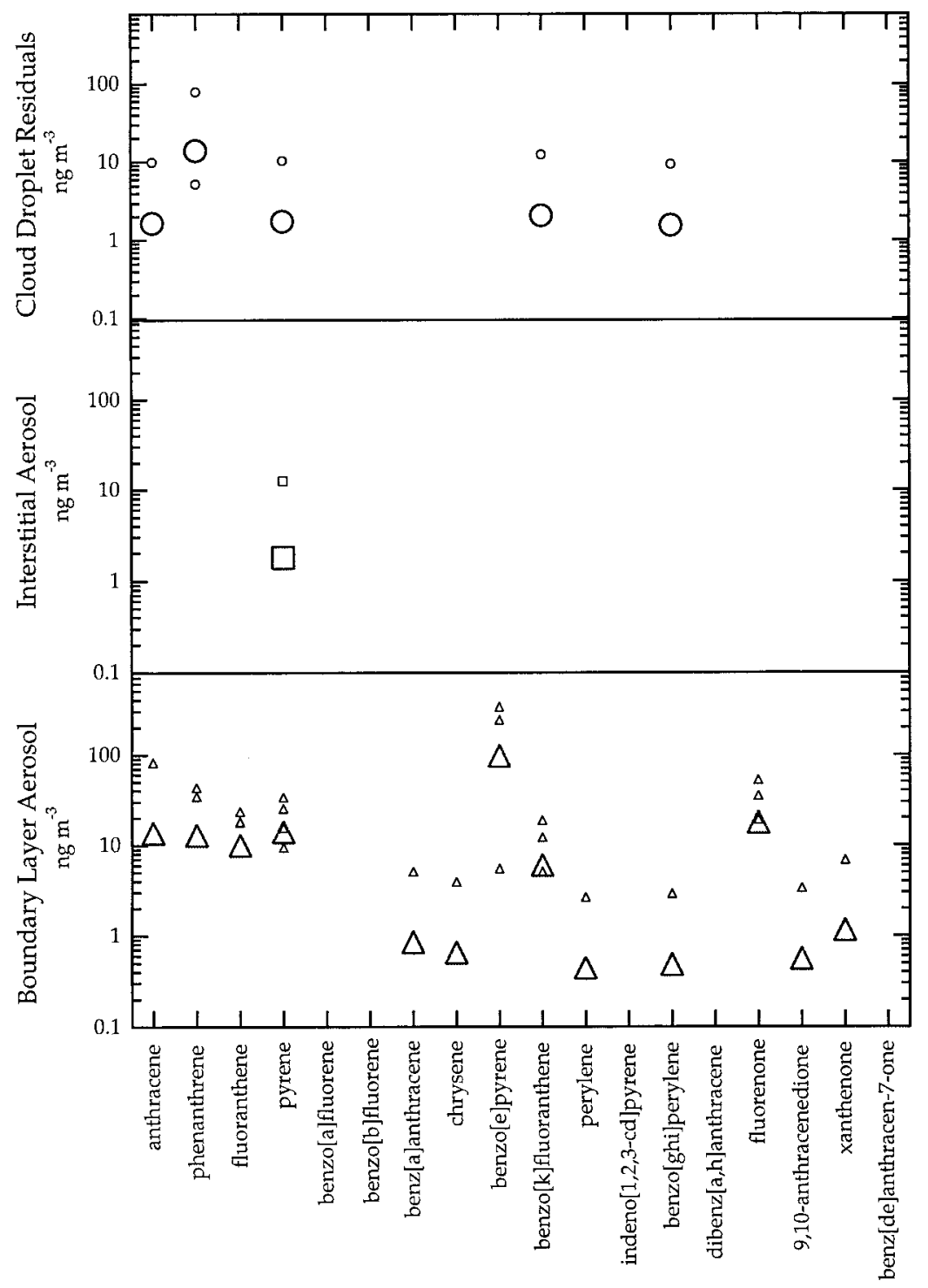

FIG. 2. Variability in, and average concentrations of, PAHs, PAQs, and PAKs in the background and ambient conditions during MAST for JDT 163, 168, 172, 178, 179, 180, and 181. Samples collected in cloud include droplet residuals and interstitial aerosol and were collected in regions without tracks. Below-cloud aerosol also is representative of background boundary layer aerosol. Large symbols represent average concentrations, and small symbols represent individual measurement from different sampling days. Measurements below detection capabilities are not shown on the graph and are averaged as $0 \mu \mathrm{g}$ $\mathrm{m}^{-3}$.

serve as $\mathrm{CCN}$, at least during the initial phases of track formation (all samples considered here are for tracks younger than $3 \mathrm{~h}$ from stack emission). However, this explanation is inconsistent with the out-of-track cloud droplet residual information showing the presence of PAHs in Fig. 2: if organics can act as $\mathrm{CCN}$ in the ambient cloud, then it would seem likely that they also can serve as CCN in ship tracks. Hence, the alternative interpretation of these data is more probable, namely, that some of the PAH-laden particles have activated in cloud to form droplets, but that CCN are sufficiently abundant that many such particles remain unactivated in the interstitial aerosol. This phenomenon has been observed in anthropogenically influenced air by Gillani et al. (1995), who note that at sufficiently high accumulation mode particle concentrations, the activation process becomes water limited and decreases the effective supersaturation in cloud. This latter interpretation is also supported by submicron size distribution measurements taken aboard the $\mathrm{C}-131 \mathrm{~A}$ that show high concentrations of particles larger than $0.1 \mu \mathrm{m}$, over $500 \mathrm{~cm}^{-3}$ in many cases, many (but not all) of which remain in the inter- 


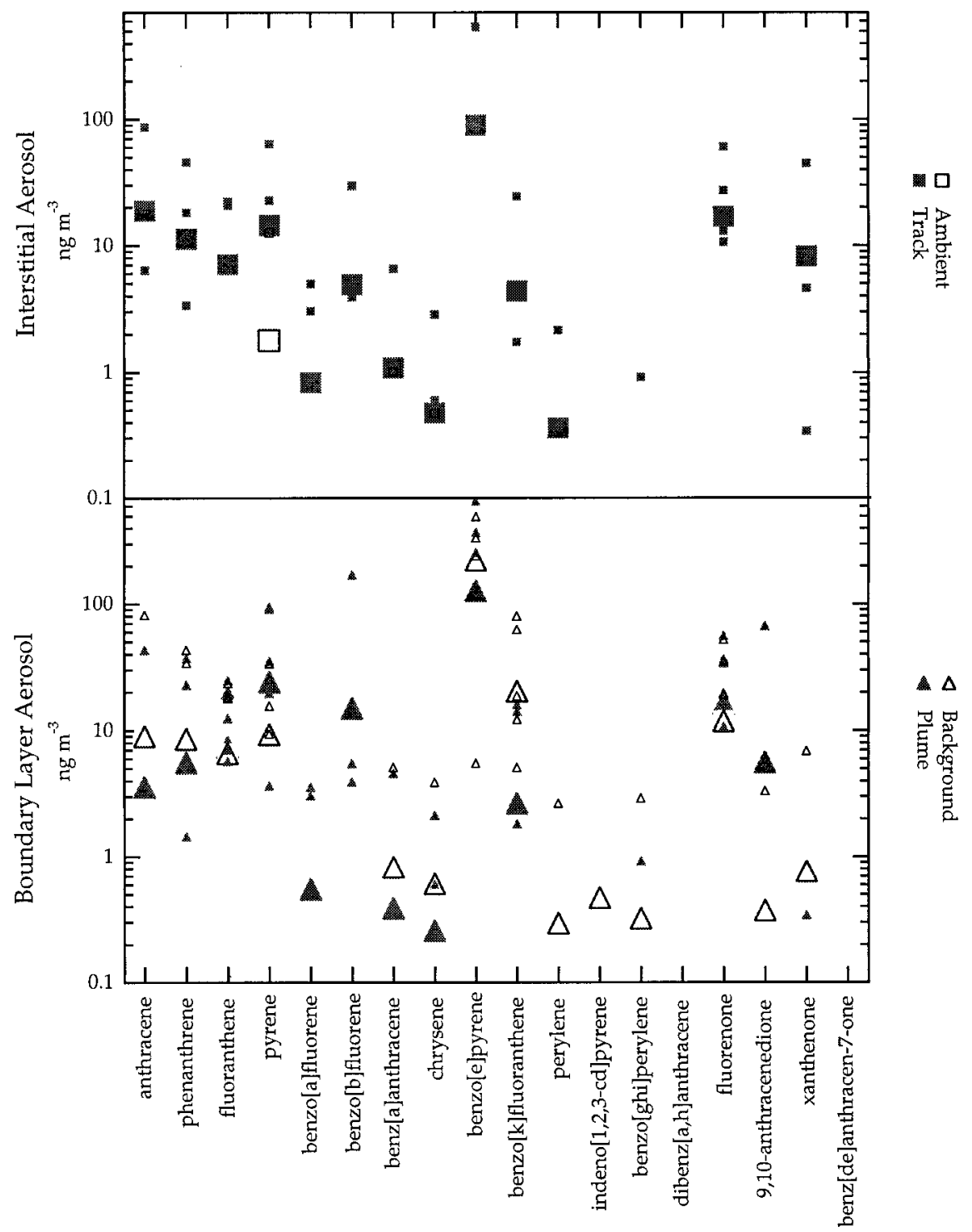

FIG. 3. Variability in, and average concentrations of, PAHs, PAQs, and PAKs detected in aerosol samples collected for JDT 159, 160,162,163,168,172, 178, 179, 180, and 181. The graph illustrates data collected in and out of track of both interstitial aerosol and boundary layer aerosol. Large symbols represent average concentrations, and small symbols represent individual measurement from different sampling days. Measurements below detection capabilities are not shown on the graph and are averaged as $0 \mu \mathrm{g} \mathrm{m}^{-3}$.

stitial phase in cloud (Noone et al. 2000a; Durkee et al. 2000a,b).

\section{c. Case studies from MAST}

Because of the complications introduced by the dayto-day variability in both the background and the ship sources in interpreting the distribution of PAHs in the boundary layer, we limit our discussion here to samples collected on two specific days during the MAST experiment. During both of these days (12 and 27 June 1994), the C131 sampled in cloud-topped boundary lay- ers where an unbroken cloud layer persisted throughout the flight.

\section{1) 12 JunE (JDT 163)}

During this flight, two diesel-powered vessels-a pusher tug (Moku Pahu) and a naval salvage ship (Safeguard) - were sampled (Gasparovic 1995). The clouds were about $300 \mathrm{~m}$ thick with the base at $200 \mathrm{~m}$ above sea level and contained droplet concentrations of about $40 \mathrm{~cm}^{-3}$. Two distinct tracks were observed.

Figure 4 shows the PAHs, PAKs, and PAQs detected 


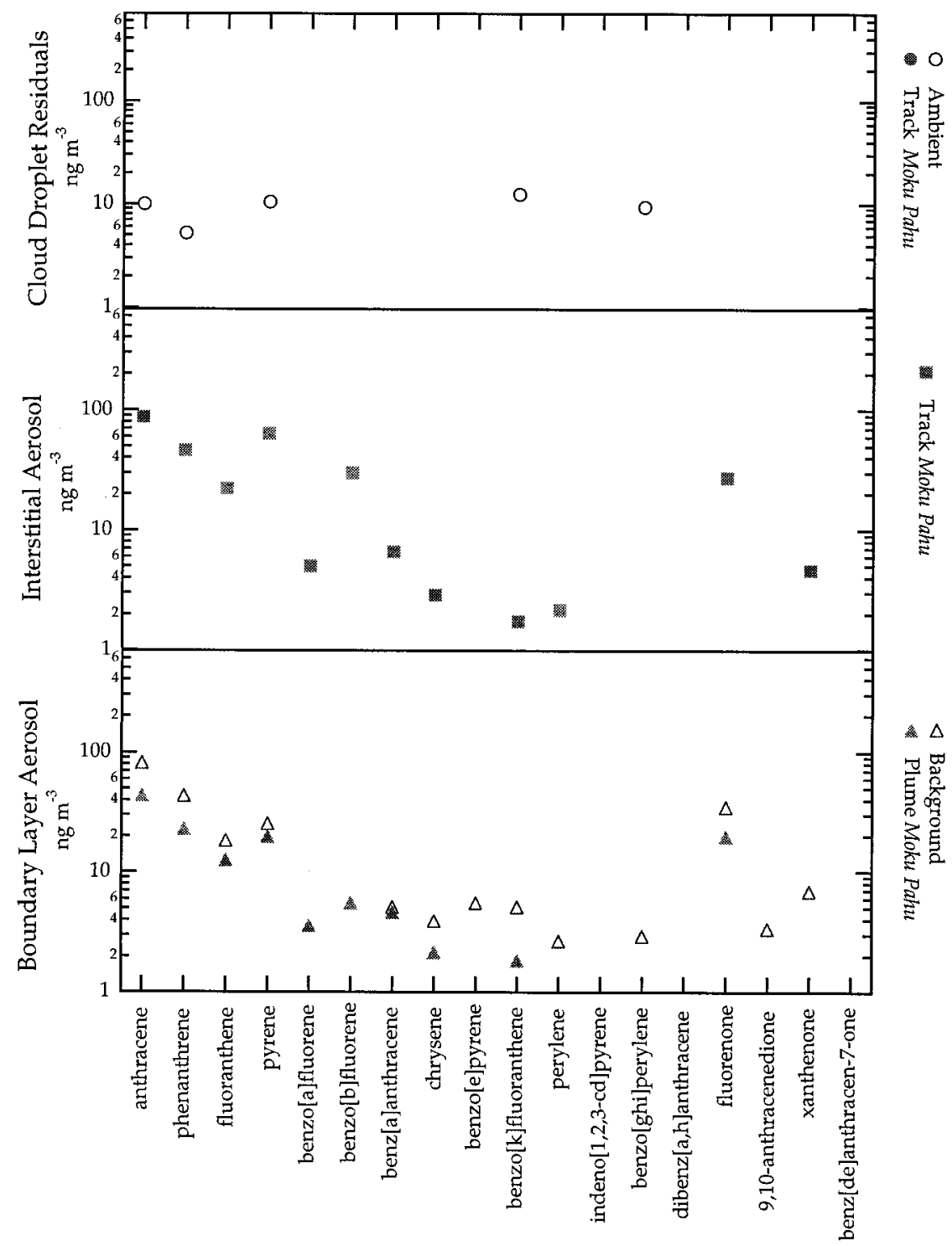

FIG. 4. Case study for MAST study day 163 (12 Jun 1994), illustrating the concentrations of PAHs, PAQs, and PAKs detected in and out of track and plumes, in and below cloud. Samples collected in cloud include droplet residuals and interstitial aerosol and were collected in regions without tracks.

in the five samples collected on this flight: track and ambient cloud droplet residuals, track interstitial aerosol, below-cloud plume and background aerosol. The background below-cloud concentrations show that many PAHs and PAKs were present in the boundary layer aerosol in the air mass surrounding the ship. For all of the compounds for which there were detectable amounts of PAH in the background aerosol, those concentrations were greater than or equal to those in the plume. However, the differences in these concentrations were not large enough to exceed both the detection uncertainty and the possibility for contamination of background samples by plume. The background concentrations of anthracene, phenanthrene, and pyrene were between 10 and $100 \mathrm{ng} \mathrm{m}^{-3}$ in both the background and the plume sample. In this case the difference between the background and plume concentrations showed few qualitative differences. The track interstitial aerosol showed similar concentrations. The residual track measurement yielded no compounds above the detection limit because of the small sample volume $\left(0.12 \mathrm{~m}^{3}\right)$, but the ambient sample indicated the presence of anthracene, phenanthrene, benzo[k]fluoranthene (or benzo[a]pyrene), and benzo[ghi]perylene. The concentrations of two of these compounds, anthracene and phenanthrene, in the droplet residuals were, however, between 6 and $20 \mathrm{ng} \mathrm{m}^{-3}$, significantly less than in the boundary layer aerosol. This result suggests that some of the background PAHs 


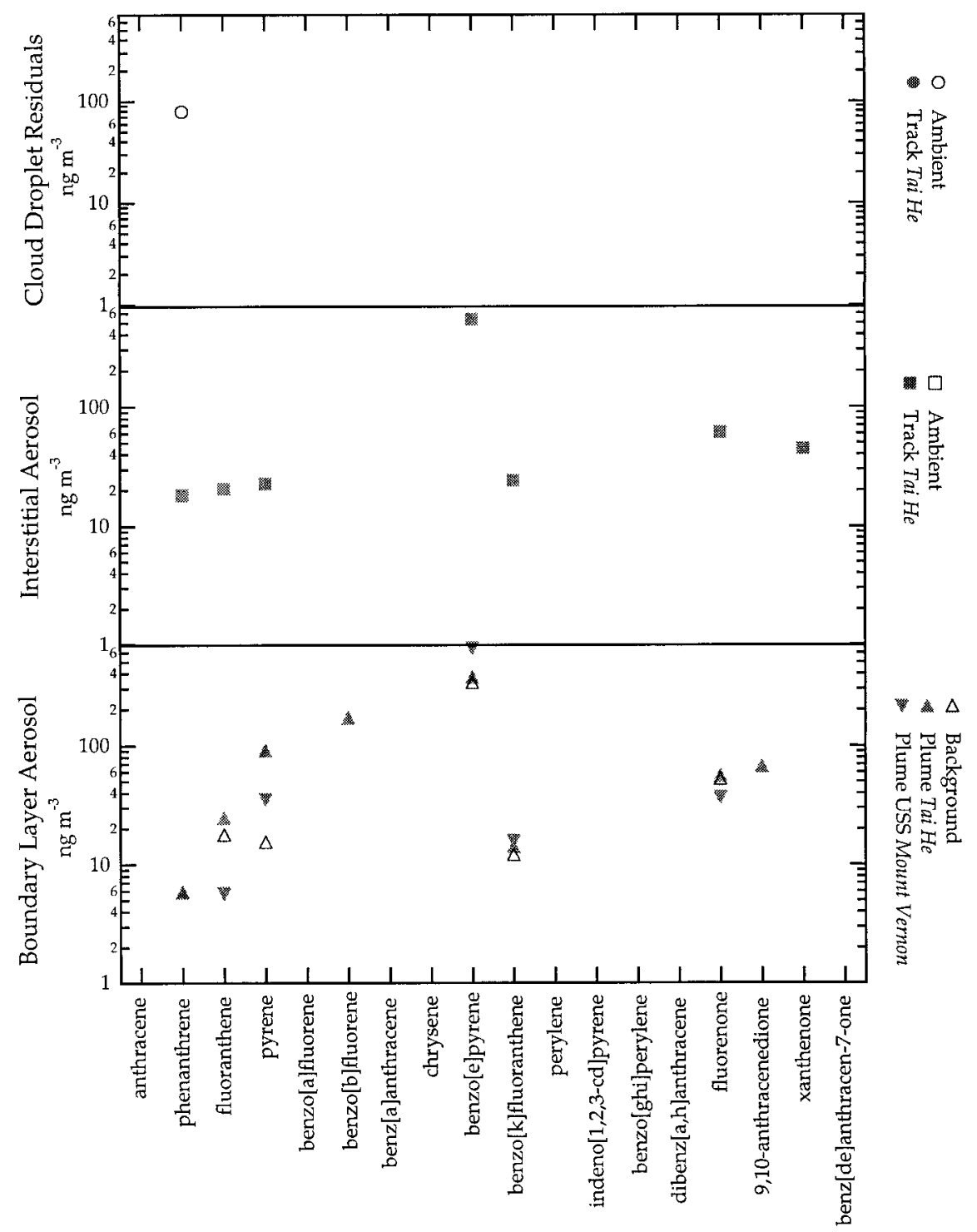

FIG. 5. Case study for MAST study day 178 (27 Jun 1994), illustrating the concentrations of PAHs, PAQs, and PAKs detected in and out of track and plumes, in and below cloud. Two plume samples were collected on this day, one from the USS Mount Vernon and the other from the Tai He.

were in particles that did activate to form droplets in the clouds sampled.

\section{2) 27 JunE (JDT 178)}

On this day, the track and plume of the container ship Tai He were sampled, as well as the plume of the naval landing ship USS Mount Vernon. The Tai He was powered by a 6-cylinder diesel engine and the Mount Vernon by a steam turbine (Gasparovic 1995). Cloud base in the sampled region was at $250 \mathrm{~m}$, cloud tops at over $400 \mathrm{~m}$, with unbroken stratocumulus for most of the sampling period. Droplet concentrations were above 150 $\mathrm{cm}^{-3}$. The high background particle and droplet concentrations showed anthropogenic influence.

Although the background air on 27 June also indicated the presence of some combustion aerosols, the intrack and plume concentrations were significantly higher than those in the surrounding air. Figure 5 shows the data from the six samples collected on this day. The ambient interstitial concentrations, most of the ambient droplet residual concentrations, and the track residual concentrations were below the detection limits. Fluoranthene is present in detectable amounts in both plume samples. In addition, the differences in the two plume samples suggest the emissions of this steam turbine en- 
gine differed significantly from that of the diesel Tai $\mathrm{He}$. Specifically, the Tai He plume showed much higher levels of phenanthrene, benzo[b]fluorene, and 9,10-anthracenedione.

\section{Partitioning of PAHs between cloud droplets and interstitial aerosol}

The activation of aerosol particles to cloud droplets is determined both by the thermodynamic conditions of the forming cloud (supersaturation and updraft velocity) and the size and composition of the aerosol particles. Identifying which particles will activate to droplets at prescribed supersaturation conditions is important to assess the radiative impact of different aerosol sources. The solubilities of the components present in the aerosol are important in determining a particle's ability to serve as CCN: the higher the concentration of soluble components, the lower the supersaturation at which a particle of a given size will activate (Pruppacher and Klett 1978). The presence of organics in this process is thought to inhibit particle activation, unless the particle is coated with a soluble layer.

Single particle analysis yielded some limited information on the organic component of the cloud droplet residual particles. Particle samples were placed in a scanning electron microscope (JEOL JSM-6300) and the size, morphology, and chemical composition of the particles were determined using electron probe X-ray microanalysis techniques (Jambers et al. 1995). The lower size limit for single particle analysis was $0.1-\mu \mathrm{m}$ radius; particles below this size were not resolved. A total of 500 particles per sample were analyzed. Once particle size and composition were determined, a hierarchical cluster analysis was performed that grouped individual particles with similar compositions (Bernard et al. 1986).

On a number of occasions, individual residual particles were observed having compositions of either entirely organic material, or organic material and chlorine. The fraction of the total number of particles containing organic material at times could be quite large; more than $36 \%$ of the 500 residual particles analyzed from ambient cloud droplets on 27 June were either organic material alone $(11.4 \%)$ or organic material plus chlorine $(25.0 \%)$ (Noone et al. 2000b).

The fact that individual residual particles were found composed entirely of organic material indicates that, at least in some of the ambient cloud cases observed, the organic material scavenged into cloud droplets was present as an external mixture in the air. If the organic material had been present as a coating on other particles or had been coagulated with sea salt or sulfate particles, these elements would have been observed in the spectra for the individual particles. These results suggest that in some cases organic particles acted as cloud condensation nuclei on their own, rather than having been associated as with inorganic species in particles of mixed
TABLE 4. Water solubilities reported for polycyclic aromatic hydrocarbons (Seidell and Linke 1952). NV, no values reported for this compound.

\begin{tabular}{lccc}
\hline \hline & Molecular & \multicolumn{2}{c}{ Solubility**** } \\
\cline { 3 - 4 } \multicolumn{1}{c}{ Polycyclic } & weight & At 300 K & At 293 K \\
aromatic hydrocarbons & amu & $\mathrm{M}$ & $\mathrm{M}$ \\
\hline Anthracene & 178.1 & $4.21 \mathrm{E}-07$ & $5.00 \mathrm{E}-07$ \\
Phenanthrene & 178.1 & $8.98 \mathrm{E}-06$ & $1.50 \mathrm{E}-05$ \\
Fluoranthene & 202.1 & $\mathrm{NV}$ & $\mathrm{NV}$ \\
Pyrene & 202.1 & $8.16 \mathrm{E}-07$ & $1.00 \mathrm{E}-06$ \\
Benzo[a]fluorene & 216.1 & $\mathrm{NV}$ & $\mathrm{NV}$ \\
Benzo[b]fluorene & 216.1 & $\mathrm{NV}$ & $\mathrm{NV}$ \\
Benz[a]anthracene & 228.1 & $4.82 \mathrm{E}-08$ & NV \\
Chrysene & 228.1 & $6.58 \mathrm{E}-09$ & $3.40 \mathrm{E}-06$ \\
Triphenylene & 228.1 & $1.67 \mathrm{E}-07$ & $\mathrm{NV}$ \\
Benzo[a]pyrene & 252.1 & $\mathrm{NV}$ & $\mathrm{NV}$ \\
Benzo[k]fluoranthene & 252.1 & $\mathrm{NV}$ & $\mathrm{NV}$ \\
Benzo[e]pyrene & 252.1 & $1.59 \mathrm{E}-08$ & $2.40 \mathrm{E}-08$ \\
Perylene & 252.1 & $1.98 \mathrm{E}-09$ & NV \\
\hline
\end{tabular}

* Solubilities are reported from Seidell and Linke (1952). Results at $300 \mathrm{~K}$ were determined by nephelometric method.

** Solubilities are reported from Seidell and Linke (1952). Results at $293 \mathrm{~K}$ were determined fluorimetrically.

composition. The results do not rule out the presence of organics in other particles, as part of internal mixtures with salts and other organics, so droplets may have also formed on mixed-composition particles.

The water solubilities of several of the PAHs, PAKs, and PAQs studied here are listed in Table 4. Values for all solubilities are less than $0.0001 \mathrm{M}$ at both 293 and $300 \mathrm{~K}$. The solubilities of these compounds in salt solutions are uncharacterized but are also likely to be low.

Phenanthrene has the highest solubility of the compounds reported in Table 4. Figure 1 illustrates that it was detected in 5 out of 9 of the ambient cloud droplet residual samples, even though only 2 of the 10 background out-of-cloud aerosol samples showed detectable concentrations. This trend suggests that phenanthrene has a higher probability of being in particles that served as CCN than the other components studied. The frequency at which a compound $(i)$ will activate to a cloud droplet can be estimated by comparing the frequency at which a compound is detected in cloud $P_{\text {cloud }}^{i}$ to the frequency at which a compound was detected in the outof-cloud aerosol $P_{\text {aerosol }}^{i}$, where in both cases the frequency from Fig. 1 has been normalized by the total number of samples in Table 3 to give the two detection probabilities. The resulting ratio,

$$
k_{\text {act }}^{i}=\frac{P_{\text {cloud }}^{i}}{P_{\text {aerosol }}^{i}},
$$

then serves as an activation index for each compound. The activation index for phenanthrene is 2.8 .

The lowest solubility reported is for benzo[e]pyrene of $2.40 \times 10^{-8} \mathrm{M}$. Benzo[e]pyrene was detected in 6 of the 10 background out-of-cloud aerosol samples, but only 3 of the 9 ambient droplet residual samples con- 


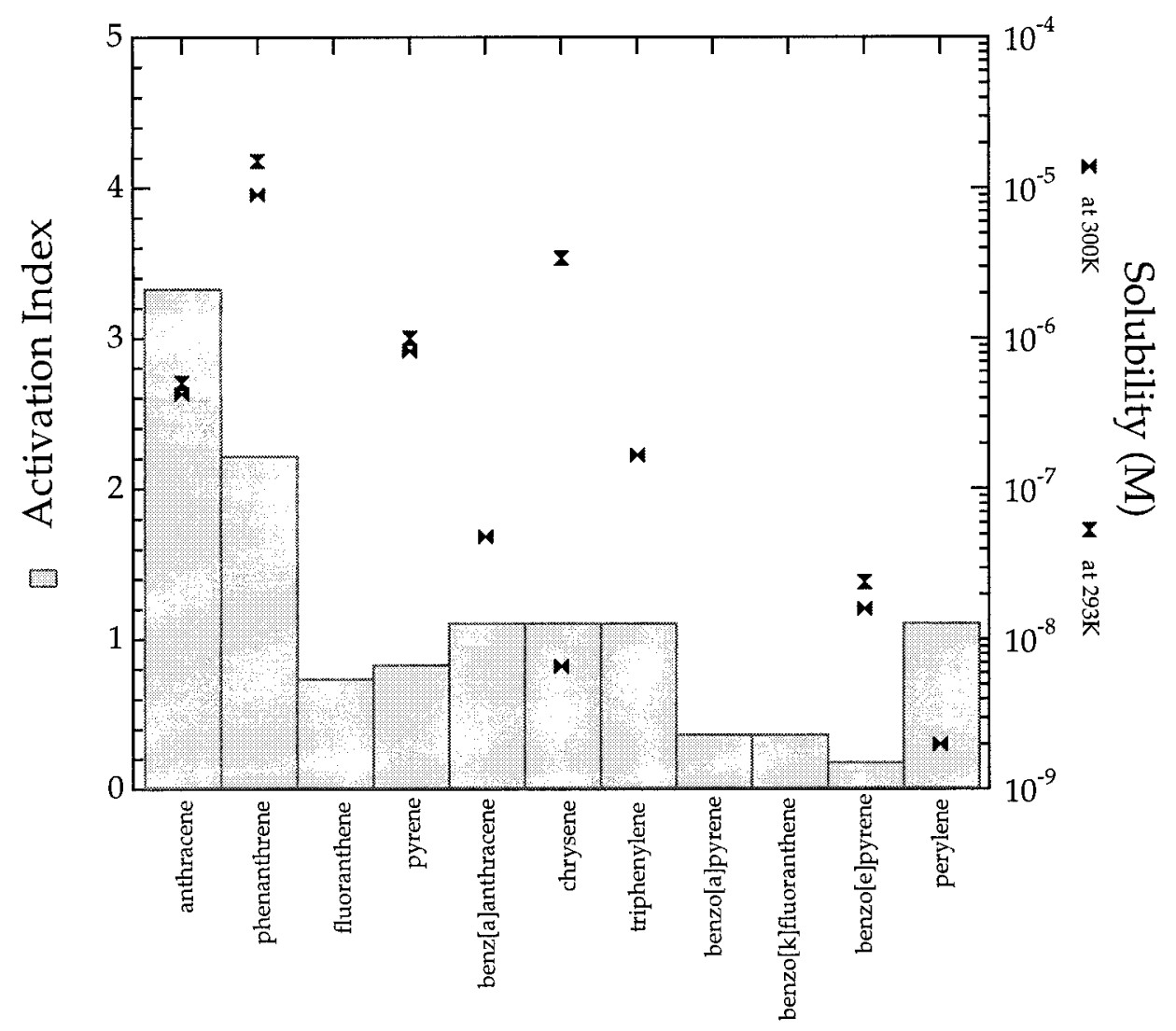

FIG. 6. Comparison of calculated activation indices and water solubilities. The activation index is the ratio of the normalized frequency of detection in cloud over the normalized frequency of detection in the boundary layer aerosol (Eq. 1). The water solubilities are reported by Seidell and Linke (1952) at temperatures of 293 and $300 \mathrm{~K}$.

tained detectable amounts. The activation index in this case would be only 0.4 .

Figure 6 compares the activation indices calculated from the MAST ambient dataset with the reported water solubilities. The activation frequencies are higher than 1.0 for 3 of the 4 species with higher water solubilities (defined here to be above $10^{-7} \mathrm{M}$ ). The compound with the lowest measured solubility at $300 \mathrm{~K}$ (benzo[e]pyrene) has the lowest activation frequency, although perylene and chrysene have lower solubility at $293 \mathrm{~K}$ but an average activation frequency (1.2). This correspondence suggests that water solubility, and associated properties such as solubility in salt solutions, are related to the ability of particles to serve as $\mathrm{CCN}$. However, it also provides a clear indication that insoluble compounds may be components in $\mathrm{CCN}$.

\section{Conclusions}

Speciated organic analysis for PAHs has established important differences in the composition of plume and background aerosol in and around ship tracks. These differences in composition provide a tracer for combustion emission sources in general and, with appro- priate source characterizations, could be used to distinguish engine and fuel traits. In addition, they provide a basis for estimating the quantitative contributions of organic species to the atmospheric aerosol. PAHs were identified in activated droplets, establishing that PAHs contribute to the mass in cloud condensation nuclei. Although PAHs have low solubilities in water, they may occur in particles of mixed composition that can serve as activation sites for cloud droplets. Those compounds with higher solubilities were usually found with higher frequency in cloud droplets. For example, of the three compounds with solubilities above $5.0 \times 10^{-7} \mathrm{M}$, both anthracene and phenanthrene have activation indices over 1.5. For the four compounds with lower solubilities, all four (benz[a]anthracene, triphenylene, benzo[e]pyrene, and perylene) have low activation indices. (Chrysene was not classified as either high or low solubility due to the large range of solubilities reported at atmospheric temperatures.)

A higher frequency of PAHs was detected in the activated droplets of ambient clouds than in the ship tracks with little evidence for PAHs remaining in the unactivated interstitial aerosol. This distinction may result from the longer time available for processing of the 
organic material present in the ambient aerosol than from that resulting from ship emissions. The ambient organic is likely to be "older" than ship track organic, allowing a longer time for aerosol processing, and resulting in the organic material being present in the larger aerosol particles. This result suggests that the particle chemistry occurring in the atmosphere plays a role in determining the population of droplets that activate. In addition to the role suggested for organics in ambient clouds as $\mathrm{CCN}$, the measurements provide indirect evidence that organics play a role in ship track $\mathrm{CCN}$ as well. Although no in-track measurements of organics in cloud droplets were collected, the interstitial measurements suggest that the fewer organics detected in track interstitial than in the plume would be consistent with partitioning to droplets. However, because of limited measurements the data are inconclusive since the role of dilution and sampling statistics was not fully characterized.

Acknowledgments. This work was funded by support from the Office of Naval Research Grant N00014-931-0872. The authors are grateful to the University of Washington Cloud and Aerosol Research Group for their assistance in collecting aerosol samples aboard the C131A, in particular Peter Hobbs, Jack Russell, and Don Spurgeon. Support of ONR Grant N00014-92-J-1587 to the University of Washington Cloud and Aerosol Research group for aircraft operations during MAST is also acknowledged.

\section{REFERENCES}

Andrews, E., and S. M. Larson, 1993: Effect of surfactant layers on the size changes of aerosol particles as a function of relative humidity. Environ. Sci. Technol., 27, 857-865.

Banisoleiman, K., and Coauthors, 1993: Marine exhaust emissions research programme: Phase II summary report. Lloyd's Register of Shipping, Croydon, United Kingdom, 19 pp. [Available from Technical Investigation, Propulsion and Environmental Engineering Department, Lloyd's Register of Shipping, Lloyd's Register House, 29 Wellesley Rd., Croydon CR0 2AJ, United Kingdom.]

_ - and Coauthors, 1994: Marine exhaust emissions research programme: Phase II transient emission trials. Lloyd's Register of Shipping, Croydon, United Kingdom, 19 pp. [Available from Technical Investigation, Propulsion and Environmental Engineering Department, Lloyd's Register of Shipping, Lloyd's Register House, 29 Wellesley Rd., Croydon CR0 2AJ, United Kingdom.]

Bernard, P., R. Van Grieken, and D. Eisma, 1986: Classification of estuarine particles using electron microprobe analysis and multivariate techniques. Environ. Sci. Technol., 20, 467-473.

Cronn, D. R., R. J. Charlson, R. L. Knights, A. L. Crittenden, and B. R. Appel, 1977: A survey of the molecular nature of primary and secondary components of particles in urban air by high resolution mass spectrometry. Atmos. Environ., 11, 929-937.

Duce, R. A., and R. B. Gagosian, 1982: The input of atmospheric nC10 to n-C30 alkanes to the ocean. J. Geophys. Res., 87, 71927200 .

- and Coauthors, 1983: Organic material in the global tropopause. Rev. Geophys. Space Phys., 21, 921-952.
Durkee, P. A., K. J. Noone, and R. T. Bluth, 2000a: The Monterey Area Ship Track experiment. J. Atmos. Sci., 57, 2523-2541.

— , and Coauthors, 2000b: The impact of ship-produced aerosols on the microstructure and albedo of warm marine stratocumulus clouds: A test of MAST hypotheses 1i and 1ii. J. Atmos. Sci., 57, 2554-2569.

Frisbie, P. R., and J. G. Hudson, 1993: Urban cloud condensation nuclei spectral flux. J. Appl. Meteor., 32, 666-676.

Gasparovic, R. F., 1995: MAST Experiment Operations Summary. The Johns Hopkins University, 300 pp.

Gillani, N. V., S. E. Schwartz, W. R. Leaitch, J. W. Strapp, and G. A. Isaac, 1995: Field observations in continental stratiform clouds: Partitioning of cloud particles between droplets and unactivated interstitial aerosols. J. Geophys. Res., 100, 18 68718706.

Grosjean, D., 1983: Polycyclic aromatic hydrocarbons in Los Angeles air from samples collected on Teflon, glass and quartz filters. Atmos. Environ., 12, 2265-2573.

Hallberg, A., and Coauthors, 1992: Phase partitioning for different aerosol species in fog. Tellus, 44B, 545-555.

Hansson, H. C., A. Wiedensohler, M. J. Rood, and D. S. Covert, 1990: Experimental determination of the hygroscopic properties of organically coated aerosol particles. J. Aerosol Sci., 21, S241S244.

Hegg, D. A., R. J. Ferek, and P. V. Hobbs, 1993: Aerosol size distributions in the cloudy atmospheric boundary layer of the North Atlantic Ocean. J. Geophys. Res., 98, 8841-8846.

Henderson, T. R., J. D. Sun, A. P. Li, R. L. Hanson, W. E. Bechtold, T. M. Harvey, J. Shabanowitz, and D. F. Hunt, 1984: GC/MS and MS/MS studies of diesel exhaust mutagenicity and emissions from chemically defined fuels. Environ. Sci. Technol., 18, 428434.

Hildemann, L. M., G. R. Cass, and G. R. Markowski, 1989: A dilution stack sampler for collection of organic aerosol emissions: Design, characterization and field tests. Aerosol Sci. Technol., 10, 193-204.

_ , G. R. Markowski, M. C. Jones, and G. R. Cass, 1991: Submicrometer aerosol mass distributions of emissions from boilers, fireplaces, automobiles, diesel trucks, and meat-cooking operations. Aerosol Sci. Technol., 14, 138-152.

Hudson, J. G., 1991: Observations of anthropogenic cloud condensation nuclei. Atmos. Environ., 25A, 2449-2455.

Jambers, W., L. De Bock, and R. Van Grieken, 1995: Recent advances in the analysis of individual environment particles. Analyst, 120, 681-692.

Kawamura, K., and R. B. Gagosian, 1987: Implications of $\omega$-oxocarboxylic acids in the remote marine atmosphere for photooxidation of unsaturated fatty acids. Nature, 325, 330-332.

Menichini, E., 1992: Urban air pollution by polycyclic aromatic hydrocarbons: Levels and sources of variability. Sci. Total Environ., 116, 109-135.

National Research Council, 1996: A Plan for a Research Program on Aerosol Radiative Forcing and Climate Change. National Academy Press, $161 \mathrm{pp}$.

Noone, K. J., J. A. Ogren, J. Heintzenberg, R. J. Charlson, and D. S. Covert, 1988: Design and calibration of a counterflow virtual impactor for sampling of atmospheric fog and cloud droplets. Aerosol Sci. Technol., 8, 235-244.

_- and Coauthors, 1992: Changes in aerosol size- and phase distributions due to physical and chemical processes in fog. Tellus, 44B, 489-504.

— - and Coauthors, 2000a: A case study of ship track formation in a polluted marine boundary layer. J. Atmos. Sci., 57, 2748-2764.

— , and Coauthors, 2000b: A case study of ships forming and not forming tracks in moderately polluted clouds. J. Atmos. Sci., 57, $2729-2747$.

Novakov, T., and J. E. Penner, 1993: Large contribution of organic aerosols to cloud-condensation-nuclei concentrations. Nature, $\mathbf{3 6 5}, 823-826$

Ogren, J. A., J. Heintzenberg, and R. J. Charlson, 1985: In-situ sam- 
pling of clouds with a droplet to aerosol converter. Geophys. Res. Lett., 12, 121-124.

Peltzer, E. T., and R. B. Gagosian, 1987: Sampling and quantitation of lipids in aerosols from the remote marine atmosphere. Anal. Chim. Acta, 198, 125-144.

Pruppacher, H. R., and J. D. Klett, 1978: Microphysics of Clouds and Precipitation. D. Reidel.

Radke, L. F., C. A. Brock, J. H. Lyons, P. V. Hobbs, and R. C. Schnell, 1989a: Aerosol and lidar measurements of hazes in mid-latitude and polar airmasses. Atmos. Environ., 23, 2417-2430.

_ J. A. Coakley, and M. D. King, 1989b: Direct and remote sensing observations of the effects of ships on clouds. Science, 246, 1146-1149.

Rogge, W. F., L. M. Hildemann, M. A. Mazurek, G. R. Cass, and B. R. T. Simoneit, 1993a: Sources of fine organic aerosol. 2. Noncatalyst and catalyst-equipped automobiles and heavy-duty diesel trucks. Environ. Sci. Technol., 27, 636-651.

,,,$--- \quad-$ and $-1993 \mathrm{~b}$ : Sources of fine organic aerosol. 3. Road dust, tire debris, and organometallic brake lining dust: Roads as sources and sinks. Environ. Sci. Technol., 27, 1892-1904.

- M. A. Mazurek, L. M. Hildemann, G. R. Cass, and B. R. T. Simoneit, 1993c: Quantification of urban organic aerosols at a molecular level: Identification, abundance and seasonal variation. Atmos. Environ., 27A, 1309-1330.

Russell, L. M., 1995: The physics and chemistry of marine aerosols. $\mathrm{Ph} . \mathrm{D}$. thesis, California Institute of Technology, 326 pp. [Avail- able from Library, California Institute of Technology, Pasadena, CA 91125.]

Saxena, P. R., and L. M. Hildemann, 1996: Water-soluble organics in atmospheric particles-A critical review of the literature and application of thermodynamics to identify candidate compounds. J. Atmos. Chem., 24, 57-109.

Schneider, J. K., R. B. Gagosian, J. K. Cochran, and T. W. Trull, 1983: Particle size distributions of $\mathrm{n}$-alkanes and $210 \mathrm{~Pb}$ in aerosols off the coast of Peru. Nature, 304, 429-432.

Seidell, A., and W. F. Linke, 1952: Solubilities of Inorganic and Organic Compounds: Supplement to the Third Edition. D. Van Nostrand, $1254 \mathrm{pp}$.

Shulman, M. L., M. C. Jacobson, R. J. Charlson, R. E. Synovec, and T. E. Young, 1996: Dissolution behavior and surface tension effects of organic compounds in nucleating cloud droplets. Geophys. Res. Lett., 23, 277-280.

Sicre, M.-A., R. B. Gagosian, and E. T. Peltzer, 1990: Evaluation of the atmospheric transport of marine-derived particles using longchain unsaturated ketones. J. Geophys. Res., 95, 1789-1795.

Tang, I. N., and H. R. Munkelwitz, 1994: Aerosol phase transformation and growth in the atmosphere. J. Appl. Meteor., 33, 791796.

Weingartner, E., U. Baltensperger, and H. Burtscher, 1995: Growth and structural change of combustion aerosols at high relative humidity. Environ. Sci. Technol., 29, 2982-2986.

Wyslouzil, B. E., K. L. Carleton, D. M. Sonnenfroh, W. T. Rawlins, and S. Arnold, 1994: Observation of hydration of single, modified carbon aerosols. Geophys. Res. Lett., 21, 2107-2110. 